\title{
The Effect of Water Content on the Gamma-ray Attenuation Factor of the Reactor Shielding Concrete
}

\author{
S. Alhajali, , M. Boush. \\ A.E.C.S, Department of nuclear engineering, \\ P.O. Box 6091, Damascus, Syria
}

\begin{abstract}
The surrounding conditions of the shielding concrete, (moisture and temperature), affect the water content within it, and therefore, the attenuation coefficient of the concrete. In this study, the impact of changing the amount of water, in four types of local candidate shielding concretes was investigated. The concrete attenuation coefficient of gamma-rays has been identified experimentally and computationally using the MCNP-4C code. The results show a significant decrease in the attenuation coefficient of each the four concrete samples due to the water losses, especially between 20100 oC.
\end{abstract}

Acceptable compatibility was noticed between the measured and calculated results of the attenuation coefficient of the studied concrete samples.

Keywords:- Radiation shielding, Reactor concrete, Gamma Attenuation.

\section{INTRODUCTION}

The concrete material is homogeneous multi-phase, consisting of inactive aggregates almost connected with each other by hardened cement paste. When water content of the concrete is changed, the attenuation properties of concrete are changed.

Concrete shields are used in radiation installations and nuclear plants to reduce radiation to permissible values. The probability of a photon interacting in a particular way with a given material, per unit path length, is called the 'linear attenuation coefficient'. For design of a dry shield, it is very important to determine this coefficient. One of material parameters that highly influence the shielding effect is its density. The concrete density can be controlled by concrete contents, mass percentage, mixing pattern and drying processes. The ratio of linear attenuation coefficient over material density $(\mu / \rho)$ is called 'mass attenuation coefficient, It is commonly addresses as the main parameter in shielding studies. The mass attenuation coefficients for a number of elements, at photon energies ranging from $1 \mathrm{keV}$ to $20 \mathrm{MeV}$ [1]. Shielding concrete contains water molecules like any other concrete, The water contributes to the attenuation process of gamma rays. Concrete properties are affected by the surrounding operational conditions, such as heat and humidity which subsequently affect the attenuation factors. Thick layers of concrete are usually used in radiation facilities. This concrete does two tasks: Consolidation the construction of the facility and there related equipment and protecting the surrounding from the high level radiations emitted from the radiation sources. Concrete shields properties are affected by the surrounding operational conditions around the facility, and one of the essential factors are the heat and humidity. As temperature rises, the concrete shields properties change and vaporizable water is lost at $100{ }^{\circ} \mathrm{C}$. There for the specific weight and the concrete attenuation coefficient can be changed.

\section{MATERIALS AND METHODS}

Four concrete mixtures recommended for shielding a nuclear reactor, which were prepared using four various types of Various gravel (It was mentioned as H-mix, F-mix, D-mix and S-mix)[2]. Table (1) shows description of the used aggregates.

The concrete samples were prepared in the form of 10 $\mathrm{x} 10 \times 10 \mathrm{~cm}$ cubes. These samples were placed in a water bath of $22^{\circ} \mathrm{C}$ for 28 days after that they left to dry at room temperature. The samples were subjected to different temperatures (from 20 to 100 degrees). The temperature rises to reach to the desired temperature in each case, and then left to cool slowly within the furnace. The samples were taken out after being cooled and placed in plastic bags and tied tightly to minimize the exchange of moisture with the surrounding medium. The sample weight was measured and determines the water content of each case.

Serpentine and hematite rocks have crushed and sieved to get the $\mathrm{BH}, \mathrm{RH}, \mathrm{BS}, \mathrm{RS}$, aggregates as described in Table (1). The sieve grades for the aggregates is shown in Table (2). While table (3)shows denotation and the mixing proportions for the four investigated mixtures.

The attenuation factor for $\gamma$ ray of Cs-137 source was measured using broad beam experimental setup in fig (1). The relation between water content and attenuation coefficient was investigated.

The attenuation coefficient was calculated using the following equation:

$$
\mu=1 / x \cdot\left(\ln \frac{I_{0}}{I}\right)
$$

Where:

$\mu:$ is the linear attenuation coefficient of the sample $\left(\mathrm{cm}^{-1}\right)$;

$I$ : gamma intensity passed the sample ;

$I_{0}$ : incident gamma intensity;

$x$ : the sample thickness. 


\section{MCNP Calculation Methods}

Due to the cost and difficulty of applying some of radiation measurements, the MCNP simulation can be used to calculate the desired results quickly and accurately at low cost. The MCNP code is one of the means used to simulate radiation measurements. Random sampling is the most common method, i.e. MCs (Monte Carlo). The Monte Carlo method solves the problems using simulation behavior for the effect of photons on materials. In radiation - transport problems (R - T), this approach is achieved by simulating the paths of "particles" (photons) from creation to termination (absorption or escape). By simulating the MCNP-4C code, the physical and radioactive quantities of each particle, such as particle flux on surface, volume, or energy distribution in a specific part of the geometry (cell) are calculated. [3].

Mainly, the composition of the concrete shield depends on the ratio of mixing and chemical composition of the main materials used. Heating concrete blocks leads to loss of water by evaporation, causing weight loss which leads to a decrease in density. The MCNP simulation was done for the sources, composition and dimensions of samples, geometry and conditions of the experiments (Fig. $1)$.

The Monte Carlo simulation method was used to calculate the linear attenuation coefficient for each concrete shield models. In this paper, using the MCNP code. The photon point source $(662 \mathrm{keV})$ located in front of two collimators followed by a $10 \mathrm{~cm}$ thick concrete shield is simulated as shown in fig (2).

Firstly, the shield was filled by vacuum, then gamma intensity passed the sample (I0) was determined by point detector tallies (F5). After that the shield is filled by concrete sample then gamma intensity passed the sample
(Ii) was calculated. then $\mu$ i for each block of concrete shield was found out, Using equation (1).

\section{RESULTS AND DISCUSSION}

The experimental and MCNP calculated results are presented in figures $3,4,5$ and 6 .

Figures 3, 4, 5 and 6 show the changing rate in gamma attenuation coefficient as a function of changing rate in water content for D-mix, F-mix, H-mix and S-mix respectively.

Analyzing these figures show the following:

> Experimentally, the changing rate of gamma attenuation coefficient decreases versus the changing rate of water content decrease in all mixes.

> The errors of experimental results don't exceed 6\%.

$>$ The calculated result errors for MCNP do not exceed $1 \%$ because nps was 106 .

$>$ Acceptable compatibility between experimental and simulated results was obtained in all cases.

$>$ The experimental and MCNP results show a 5\% difference.

\section{CONCLUSION}

Water loss case of the shielding concrete water decreases the gamma-ray attenuation characteristics for all concrete mixes. The attenuation coefficient for gamma radiations of local concrete mixes was simulated using the MCNP code. The simulation results were compared with experimental ones. Acceptable compatibility was obtained between the MCNP simulation and experimental results. Thus, this study has demonstrated that the MCNP simulation provides a useful tool to determine the attenuation coefficient for Gamma radiations.

\begin{tabular}{|c|c|}
\hline Aggregates type & The source and contents \\
\hline $\mathrm{BF}$ & $\begin{array}{c}\text { River natural coarse aggregates, } \\
65 \% \mathrm{SiO}_{2}+17 \% \mathrm{CaCO}_{3}+18 \% \mathrm{CaAl}_{2}\left(\mathrm{Si}_{2} \mathrm{Al}_{2}\right) \mathrm{O}_{10}(\mathrm{OH})_{2}\end{array}$ \\
\hline $\mathrm{RF}$ & $\begin{array}{c}\text { River natural fine aggregates, } \\
50 \% \mathrm{SiO}_{2}+20 \% \mathrm{CaCO}_{3}+25 \% \mathrm{CaAl}_{2}\left(\mathrm{Si}_{2} \mathrm{Al}_{2}\right) \mathrm{O}_{10}(\mathrm{OH})_{2}+5 \% \mathrm{~K}, \mathrm{Fe}, \mathrm{Al} \text {, silicate }\end{array}$ \\
\hline $\mathrm{BD}$ & $\begin{array}{l}\text { Dolomite crushed coarse aggregates, } \\
97 \% \mathrm{CaMg}\left(\mathrm{CO}_{3}\right)_{2}+3 \% \mathrm{CaCO}_{3}\end{array}$ \\
\hline $\mathrm{RD}$ & $\begin{array}{l}\text { Dolomite crushed fine aggregates, } \\
98 \% \mathrm{CaMg}\left(\mathrm{CO}_{3}\right)_{2}+2 \% \mathrm{CaCO}_{3}\end{array}$ \\
\hline $\mathrm{BH}$ & \multirow{2}{*}{$\begin{array}{c}\text { Hematite crushed coarse and fine aggregates, } \\
(43-100) \% \mathrm{Fe}_{2} \mathrm{O}_{3} \text { (and other Fe oxides) + (5-50\%) } \mathrm{TiO}_{2}+\mathrm{CaCO}_{3}+\mathrm{CaMg}\left(\mathrm{CO}_{3}\right)\end{array}$} \\
\hline RH & \\
\hline BS & \multirow{2}{*}{$\begin{array}{l}\text { Serpentine Crushed coarse and fine aggregates, } \\
(93-100 \%) 3 \mathrm{MgO} .2 \mathrm{SiO}_{2} .2 \mathrm{H}_{2} \mathrm{O}\end{array}$} \\
\hline RS & \\
\hline CS & Natural sea-side sands with high content of heavy metallic minerals \\
\hline
\end{tabular}

Table 1:- Description, denotation, and XRD results of the used aggregates 
ISSN No:-2456-2165

\begin{tabular}{|c|c|c|c|c|c|c|c|c|c|}
\hline \multirow{2}{*}{$\begin{array}{c}\text { Sieve No. } \\
\text { (inch) }\end{array}$} & \multicolumn{9}{|c|}{ Total Passed (\%) } \\
\cline { 2 - 11 } & BF & RF & BD & RD & BH & RH & BS & RS & CS \\
\hline $11 / 2$ & 100 & 100 & 100 & 100 & 100 & 100 & 100 & 100 & 100 \\
\hline 1 & 97 & 100 & 100 & 100 & $100-87$ & 100 & 98 & 100 & 100 \\
\hline $3 / 4$ & 90 & 100 & $98-81$ & 100 & $100-75$ & 100 & 93 & 100 & 100 \\
\hline $1 / 2$ & 60 & 100 & $88-2$ & 100 & $93-51$ & 100 & 79 & 100 & 100 \\
\hline $3 / 8$ & 31 & 100 & $51-0$ & 100 & $83-35$ & 100 & 49 & 100 & 100 \\
\hline N4 & 0 & 92 & 0 & 96 & $24-0.5$ & $100-98$ & 10 & 100 & 94 \\
\hline N8 & 0 & 86 & 0 & 52 & $0.75-0$ & $71-61$ & 0.5 & 77 & 87 \\
\hline N16 & 0 & 84 & 0 & 26 & 0 & $36-32$ & 0 & 53 & 75 \\
\hline N30 & 0 & 83 & 0 & 16 & 0 & $20-18$ & 0 & 36 & 59 \\
\hline N50 & 0 & 45 & 0 & 11 & 0 & 11 & 0 & 25 & 15 \\
\hline N100 & 0 & 8 & 0 & 7 & 0 & 6 & 0 & 15 & 1 \\
\hline N200 & 0 & 2 & 0 & 4 & 0 & $4-3$ & 0 & 8 & 0.3 \\
\hline base & 0 & 0 & 0 & 0 & 0 & 0 & 0 & 0 \\
\hline
\end{tabular}

Table 2:- Sieve grading for the used aggregates.

\begin{tabular}{|c|c|c|c|c|c|c|c|}
\hline \multirow[b]{2}{*}{ Mixture } & \multicolumn{5}{|c|}{ Mixture component } & \multirow{2}{*}{$\begin{array}{c}\text { Abrams } \\
\text { Cone slump } \\
(\mathrm{cm})\end{array}$} & \multirow{2}{*}{$\begin{array}{c}\text { Fresh } \\
\text { Specific } \\
\text { weight } \\
\left(\mathrm{g} . \mathrm{cm}^{-3}\right)\end{array}$} \\
\hline & cement & water & Fine aggregates & $\begin{array}{c}\text { coarse } \\
\text { aggregates }\end{array}$ & plasticizer & & \\
\hline D-mix & 1 & 0.55 & $3.3(\mathrm{RD})$ & $2.2(\mathrm{BD})$ & 0.015 & 10 & 2.50 \\
\hline F-mix & 1 & 0.55 & $1.8(\mathrm{RF})$ & $4.2(\mathrm{BF})$ & 0.015 & 20 & 2.57 \\
\hline H-mix & 1 & 0.50 & $\begin{array}{c}0.9(\mathrm{RH}) \\
+0.675(\mathrm{CS})\end{array}$ & $2.9(\mathrm{BH})$ & 0.015 & 5 & 2.84 \\
\hline S-mix & 1 & 0.55 & $3.2(\mathrm{RS})$ & $1.3(\mathrm{BS})$ & 0.015 & 2.5 & 2.24 \\
\hline
\end{tabular}

Table 3:- Denotation and mixing proportion for the investigated concrete mixtures.

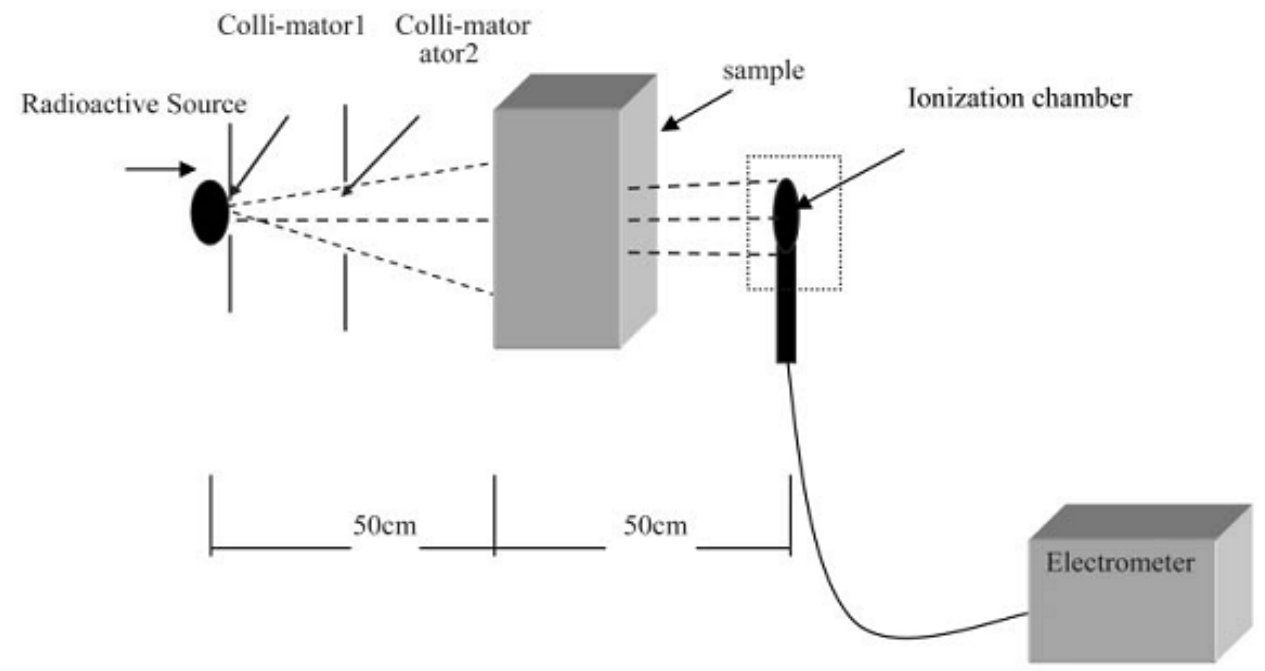

Fig 1:- Experemental schematic draw of the setup of the measurements using Cs-137 source. 


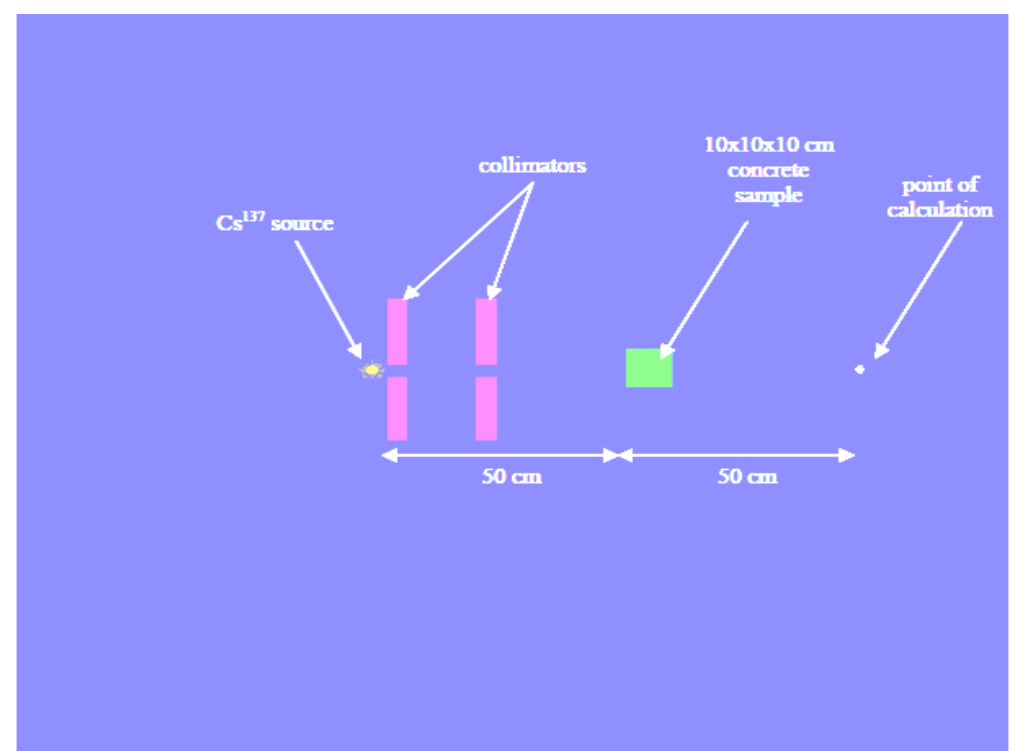

Fig 2:- MCNP schematic draw of the setup of the measurements using Cs-137 source.

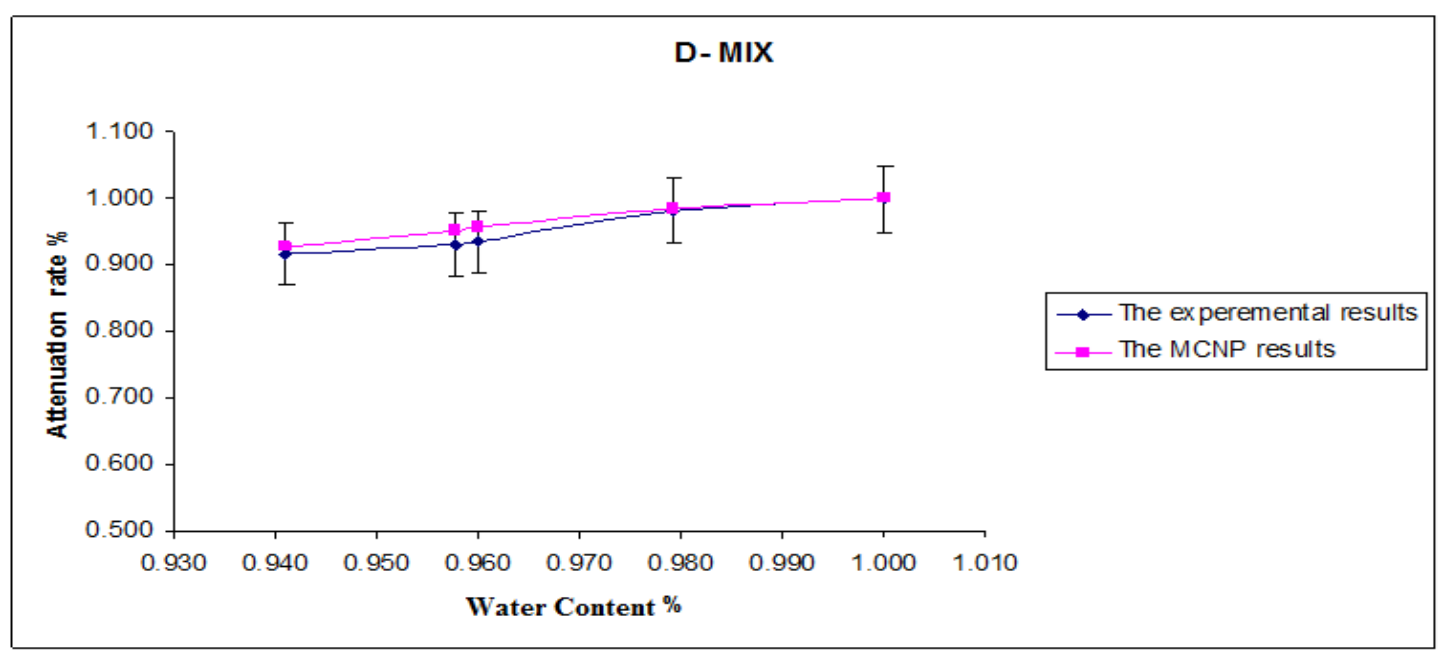

Fig 3:- Changing rate in Gamma attenuation coefficient curves as functions of changing rate in water content.

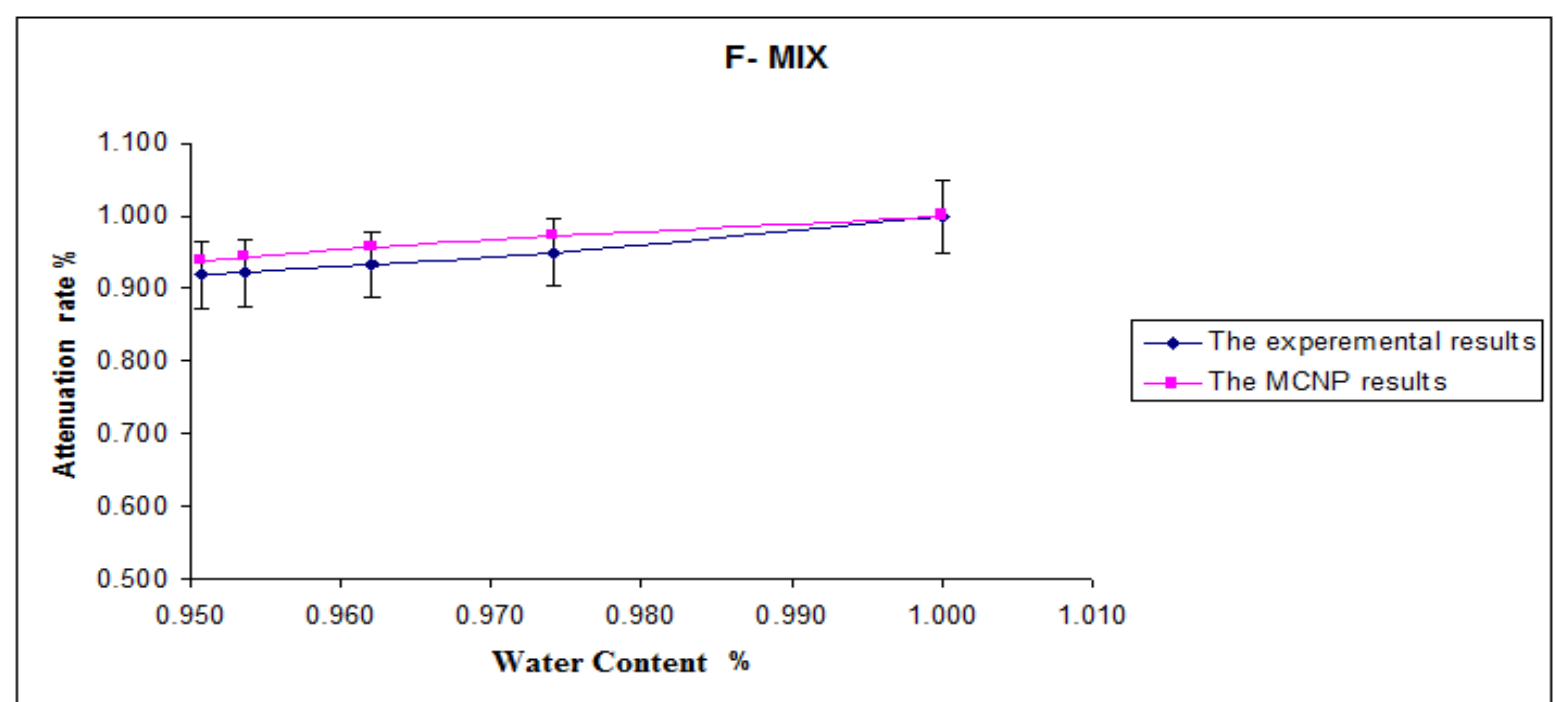

Fig 4:- Changing rate in Gamma attenuation coefficient curves as functions of changing rate in water content. 


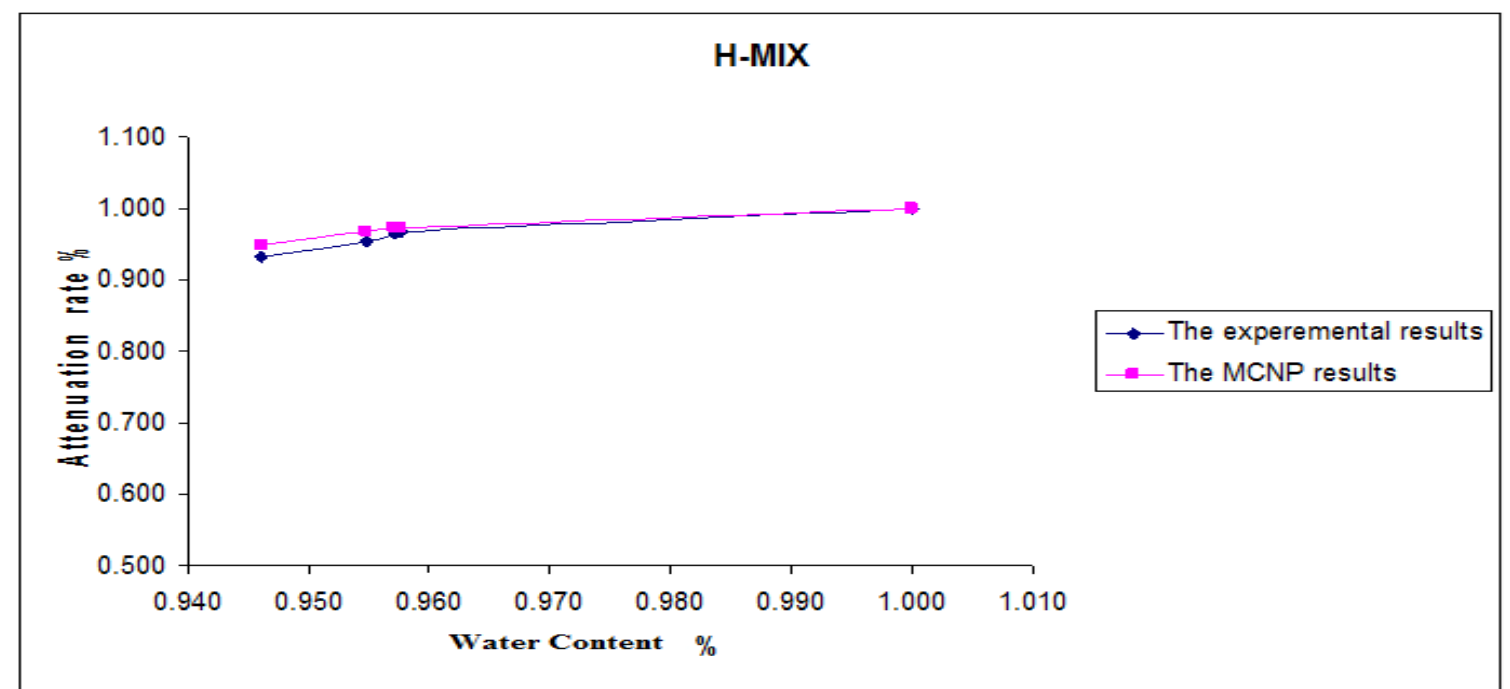

Fig 5:- Changing rate in Gamma attenuation coefficient curves as functions of changing rate in water content.

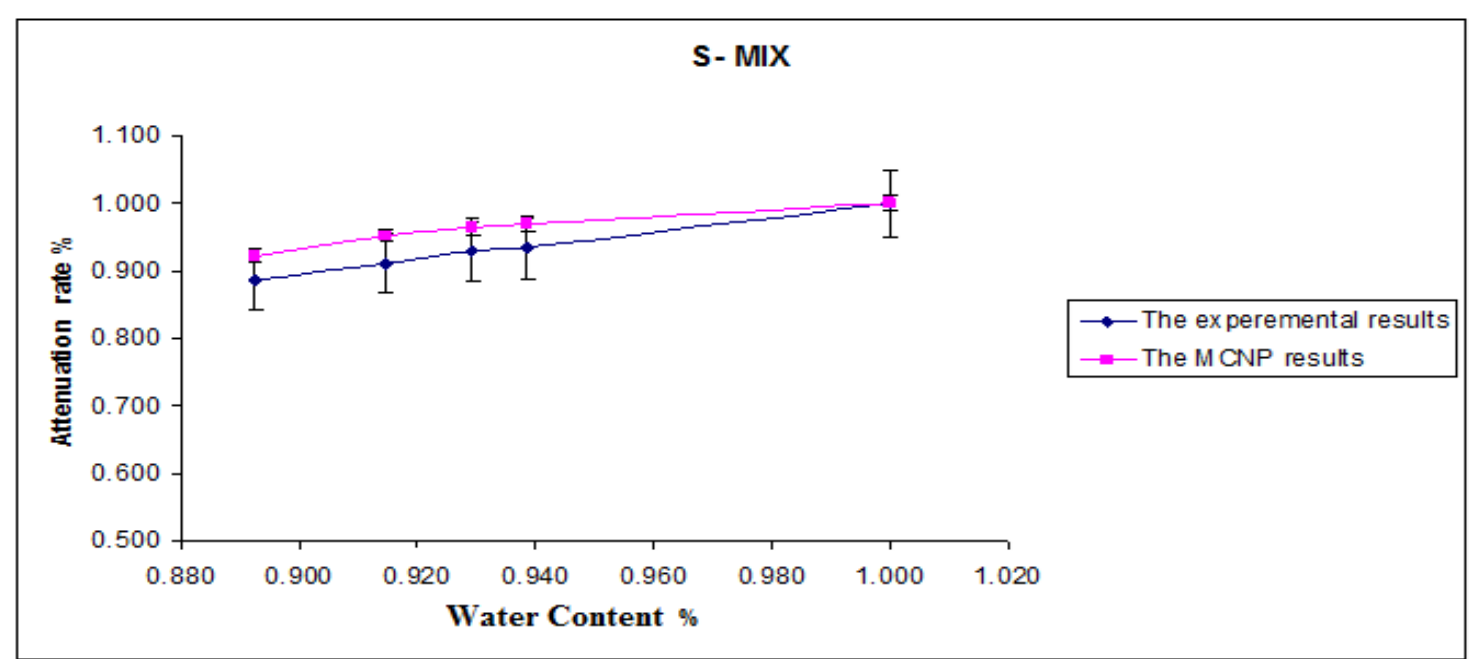

Fig 6:- Changing rate in Gamma attenuation coefficient curves as functions of changing rate in water content.

\section{ACKNOWLEDGMENT}

The authors would like to thank Prof. I. Othman (D. G. of AECS) for his encouragement.

\section{REFERENCES}

[1]. Lamarash J.R. et al. (2001) Introduction to Nuclear Engineering, Prentice Hall. Inc. New Gercy;

[2]. S. Yousef b, M. AlNassar a, B. Naoom c, S. Alhajali c, M.H. Kharita, Heat effect on the shielding and strength properties of some local concretes. Progress in Nuclear Energy 50 (2008) 22e26;

[3]. MCNP4C User's Manual (2000) Radiation Safety information Computational Centre, Los Alamos Laboratory, Los Alamos, NM;

[4]. Fu Shen, Zhiwen Fan, Hongxiang An, Xiaowei Xiong, Application of MCNP to Study the shielding Effect of Zinc Bromide Solution, Progress in NUCLEAR SCIENCE and TECHNOLOGY, Vol. 1, p.98-101 (2011).
[5]. Kaplan, M. F. (1989) Concrete Radiation Shielding. Longman Scientificand Technology, Longman Group UK Limited, Essex, England.

[6]. ASTM C 637-84: standard specifications for aggregates for radiation shielding concrete. 